\title{
Lung cancer gene therapy: Transferrin and hyaluronic acid dual ligand-decorated novel lipid carriers for targeted gene delivery
}

\author{
BIN ZHANG ${ }^{1}$, YUEYING ZHANG ${ }^{2}$ and DONGMEI YU ${ }^{3}$ \\ ${ }^{1}$ Department of Oncology, Shandong Jining No. 1 People's Hospital, Jining, Shandong 272011; ${ }^{2}$ Department of Experimental \\ Pathology, Institute of Basic Medicine, Shandong Academy of Medical Sciences, Jinan, Shandong 250062; \\ ${ }^{3}$ Department of Public Health, Shandong Jining No. 1 People's Hospital, Jining, Shandong 272011, P.R. China
}

Received June 29, 2016; Accepted November 15, 2016

DOI: $10.3892 /$ or.2016.5298

\begin{abstract}
To achieve lung cancer gene therapy, nanocarriers decorated with different ligands were used. Surface decoration and nanoparticulate system will assist in targeting the gene to specific cells and tissues, such as cancers and diseased organs. The aim of this research was to develop a dual ligand-decorated nanocarriers, which could target the tumor cells through receptor-mediated pathways to increase the uptake of genetic materials. Transferrin (Tf) and hyaluronic (HA) containing polyethylene glycoldistearoylphosphatidylethanolamine (Tf-PEG-DSPE and HA-PEG-DSPE) ligands were synthesized. Novel Tf and HA ligand-decorated, plasmid-enhanced green fluorescent protein loaded nanostructured lipid carriers (Tf/HA-pDNA NLC) was constructed. Physicochemical properties such as morphology, size, and $\zeta$-potential as well as release properties were evaluated. The in vitro and in vivo gene transfection efficiency of Tf/HA-pDNA NLC was evaluated in lung adenocarcinoma A549 cells and lung cancer bearing animal models. Tf/HA-pDNA NLC displayed significantly higher transfection efficiency than undecorated DNA-NLCs and single ligand-decorated NLCs in vitro and in vivo. The newly constructed NLCs could successfully load gene; and Tf and HA functioned as excellent targeting ligands to improve the cell targeting ability of the gene-loaded nanocarriers. The resulting dual ligands decorated vectors could be a promising targeted gene delivery system for the lung cancer treatment.
\end{abstract}

\section{Introduction}

Lung cancer is the most prevalent histological cancer subtype and is the leading cause of cancer-related death (1). Current

Correspondence to: Dr Dongmei Yu, Department of Public Health, Shandong Jining No. 1 People's Hospital, No. 6 Jiankang Road, Jining, Shandong 272011, P.R. China

E-mail: yudjnph@163.com

Key words: lung cancer, gene therapy, lipid carriers, dual liganddecorated, transferrin, hyaluronic acid standard treatment for lung cancer contains chemotherapy and radiotherapy. However, major problems with the above treatment modalities are the lack of tumor specificity giving rise to dose-limiting toxicity, and resistance to the treatments, as well as predicted poor outcomes for lung metastatic treatment (2-4). Thus, novel therapeutic strategies are in high demand.

Gene therapy has been proved to be a promising strategy for the treatment of genetically based diseases, such as lung cancer (5-8). Using this strategy, cancer cytotoxicity can be obtained by replacing mutated genes with functional analogues or introducing a suicide gene into the malignant cells $(2,9)$. However, one of the major challenges of genebased cancer therapy is to achieve specific, efficient and safe systemic delivery of genes in vivo (10). Several delivery strategies have been established to overcome the hurdles of in vivo gene delivery and enhance the efficacy of cancer therapy: modified oligonucleotides, nanocarriers, and tumor-targeted nanocarriers (11-13). The third-generation delivery strategy (tumor-targeting approach) has recently emerged to add surface modifications to the nanocarriers, which allow specific binding to the target cancer cells and deliver the gene into the cancer cells through receptor-mediated endocytosis.

Nanocarriers such as cationic liposomes, lipoplexes, nanoparticles, micelles, solid lipid nanoparticles (SLN), nanostructured lipid carriers (NLC), exhibit many advantages as potential candidates for efficient non-viral gene delivery systems (14-16). Among them, NLC, composed of a blend of the solid lipid and the liquid lipid, exhibit superior advantages over other colloidal carriers mentioned above: an increase in chemical stability of the incorporated drugs, higher drug loading capacity, lower toxicity and controlled release (17). In order to enhance the tumor target, transferrin (Tf) and hyaluronic acid (HA) dual ligand-decorated NLC for targeted gene delivery were designed in the current study.

Tf, a 698-residual protein, has been used as a cancertargeting agent in multiple delivery systems since the transferring receptor is overexpressed in most cancer cells containing lung carcinoma cells (18). HA is a biodegradable, biocompatible, and polyanionic glycol amino glycan (19). It has an important biological role in the cell adhesion, migration, invasion, proliferation, differentiation and angiogenesis by binding to cell specific receptors such as glycoprotein CD44 (20). It has already been reported that the CD44 
receptors are highly expressed in majority of non-small cell lung cancers (NSCLC) (21). Pan et al constructed HA and Tf co-modified $\mathrm{Fe}_{3} \mathrm{O}_{4}$ nanoparticles for dual-targeting magnetic resonance imaging of tumors in vivo. Results showed that this system had a high targeting ability towards tumor cells and excellent biocompatibility (22). To date, no studies have reported HA and Tf dual ligand-decorated NLC for targeted gene delivery to lung carcinoma cells.

Lung adenocarcinoma A549 cells are adenocarcinomic human alveolar basal epithelial cells (23). The A549 cell line was first developed in 1972 by Giard et al through the removal and culturing of cancerous lung tissue in the explanted tumor of a 58-year-old Caucasian male. In nature, these cells are squamous and responsible for the diffusion of some substances, such as water and electrolytes, across the alveoli of lungs. When A549 cells are cultured in vitro, they grow as monolayer cells, adherent or attaching to the culture flask. Another characteristic of these cells is that they are able to synthesize lecithin and contain high level of unsaturated fatty acids, which are important to maintain the membrane phospholipids in cells. A549 cells are widely used as an in vitro model for a type II pulmonary epithelial cells for drug metabolism and as a transfection host. Thus, A549 cells were used also in this work.

The aim of the present study was to construct dual ligand( $\mathrm{Tf}$ and HA) modified NLC, the novel nanocarrier for delivery of a gene, to achieve the tumor target. Plasmid-enhanced green fluorescent protein was used as the model DNA (pDNA). We evaluated the systemic delivery efficiency using human lung adenocarcinoma A549 cell-bearing mouse model.

\section{Materials and methods}

Materials. Plasmid encoding enhanced green fluorescent protein (pEGFP) was obtained from Clontech (Palo Alto, CA, USA). Transferrin (Tf), glycerol monostearate (GM), 3-(4,5-dimethylthiazol-2-yl)-2,5-diphenyl-tetrazolium bromide (MTT), soybean phosphatidylcholine (SPC) were purchased from Sigma-Aldrich Co. Ltd. (Shanghai, China). Soybean oil (SO) was purchased from Guangzhou Hanfang Pharmaceutical Co., Ltd. (Guangzhou, China). Hyaluronic acid (HA, MW $5 \mathrm{kDa}$ ) was provided by Shandong Freda Biochem Co., Ltd. (Ji'nan, China). 1,2-dioleoyl-3-trimethylammonium propane (DOTAP) was purchased from Avanti Polar Lipids (Alabaster, AL, USA). Polyethylene glycol-distearoylphosphatidylethanolamine (PEG-DSPE) was purchased from CordenPharma International (Plankstadt, Germany). Quant-iT ${ }^{\mathrm{TM}}$ PicoGreen ${ }^{\circledR}$ dsDNA quantitation reagent was obtained from Invitrogen by Life Technologies (Carlsbad, CA, USA). Lipofectamine ${ }^{\circledR}$ 3000 transfection reagent was obtained from Thermo Fisher Scientific (Waltham, MA, USA). All of the other chemicals were of analytical or high performance liquid chromatography (HPLC) reagent grade.

Cells. A549 cells were obtained from American Type Culture Collection (ATCC, Manassas, VA) and cultured in Dulbecco's modified Eagle's medium (DMEM, Sigma, St. Louis, MO, USA) supplemented with $10 \%$ fetal bovine serum (FBS) (Fisher Chemicals, Fairlawn, NJ, USA) in a $5 \% \mathrm{CO}_{2}$ fully humidified atmosphere.
Animals. BALB/c nude mice (4-6 weeks old, 18-22 g weight) were purchased from Beijing Vital River Experimental Animal Technical Co., Ltd (Beijing, China). Mice were maintained under $25^{\circ} \mathrm{C}$ and $55 \%$ of humidity with free access to standard water and chow. Lung cancer-bearing mice were prepared by subcutaneous inoculating a suspension of A549 cells $\left(1 \times 10^{7}\right.$ cells) into the right armpit of BALB/c mice (24). Tumors were $8-10 \mathrm{~mm}$ in diameter before initiation of the in vivo studies. Animal experiments were complied with the Animal Management Rules of the Ministry of Health of the People's Republic of China.

Synthesis of Tf-PEG-DSPE and HA-PEG-DSPE. Tf-PEGDSPE ligands were synthesized using the method reported previously (24). Briefly, Tf was first modified with one equivalent of Traut's reagent to complete thiolation of Tf. The PEG-DSPE was then added into one equivalent of thiolated $\mathrm{Tf}$ solution, and the mixture was incubated for $2 \mathrm{~h}$ at room temperature, with gentle stirring. The product was dialyzed against Milli-Q water for $24 \mathrm{~h}$ to form Tf-PEG-DSPE solution. The mixture was centrifuged at $10,000 \mathrm{xg}$ for $30 \mathrm{~min}$ at $4^{\circ} \mathrm{C}$, and then resuspended in PBS ( $\mathrm{pH}$ 7.4).

HA-PEG-DSPE ligands were synthesized as follows (25). Briefly, PEG-DSPE and one equivalent of HA were dissolved in $20 \mathrm{ml}$ of $\mathrm{N}, \mathrm{N}$-dimethylformamide (DMF), followed by adding 2 equivalent of 1-ethyl-3-(3-dimethylamino-propyl) carbodimide (EDC) and one equivalent of N-hydroxysuccinimide (NHS). The reaction proceeded overnight at room temperature under the protection of nitrogen. Then, the resulting solution was concentrated under reduced pressure and dialyzed using a dialysis bag (molecular weight cut-off 12,000-14,000). Finally, the HA-PEG-DSPE was obtained after lyophilization using a freeze dryer.

Chemical structures of Tf-PEG-DSPE and HA-PEG-DSPE were analyzed by ${ }^{1} \mathrm{H}-\mathrm{NMR}$ spectroscopy. Tf-PEG-DSPE, $\delta$ (ppm): $0.89\left(\mathrm{CH}_{3}\right), 1.21-1.86\left(\mathrm{CH}_{2}\right.$ of PEG-DSPE), 2.45 $\left(\mathrm{CH}_{2} \mathrm{CO}, \mathrm{NHCO}\right), 3.28\left(\mathrm{CH}_{2} \mathrm{~N}\right), 3.36-3.48\left(\mathrm{OCH}_{2}\right), 4.03$ (NHCO), and $6.54(\mathrm{NH})$. HA-PEG-DSPE, $\delta(\mathrm{ppm}): 0.95$ $\left(\mathrm{CH}_{3}\right), 1.31-1.95\left(\mathrm{CH}_{2}\right.$ of PEG-DSPE), 2.01 (OH of HA), 2.29 ( $\mathrm{NHCO}), 2.65\left(\mathrm{CH}_{2} \mathrm{CO}\right), 3.03-3.51(\mathrm{CH}$ of $\mathrm{HA}), 3.83\left(\mathrm{OCH}_{2}\right)$, $4.16(\mathrm{NHCO})$, and $10.84(\mathrm{OH})$.

Preparation of NLC and incorporation of $p D N A$. The Tf-PEG-DSPE and HA-PEG-DSPE modified, pDNA incorporated NLC (Tf/HA-pDNA NLC) were prepared according to previous studies (26). Briefly, $500 \mathrm{mg} \mathrm{GM}, 200 \mathrm{mg}$ SPC were dissolved in $10 \mathrm{ml}$ warm SO $\left(70^{\circ} \mathrm{C}\right)$ to obtained the oil phase. Ten milliliters $(1 \mathrm{mg} / \mathrm{ml})$ pDNA, $1 \mathrm{~g}$ Tf-PEG-DSPE, $1 \mathrm{~g}$ HA-PEG-DSPE, and $50 \mathrm{mg}$ DOTAP were dissolved in $30 \mathrm{ml}$ deionized water to form an aqueous phase. The resultant oil phase was quickly dispersed into aqueous phase under mechanical stirring with $400 \mathrm{rpm}$ in water bath $\left(70^{\circ} \mathrm{C}\right)$ for $5 \mathrm{~min}$. The obtained complex solution was cooled to room temperature until Tf/HA-pDNA NLC was obtained (Fig. 1).

Tf-PEG-DSPE modified, pDNA incorporated NLC (Tf-pDNA NLC) was prepared as described above only without HA-PEG-DSPE in aqueous phase, using $2 \mathrm{~g}$ of Tf-PEG-DSPE in total. HA-PEG-DSPE modified, pDNA incorporated NLC (HA-pDNA NLC) was prepared as described above only without Tf-PEG-DSPE in aqueous phase, using $2 \mathrm{~g}$ of 

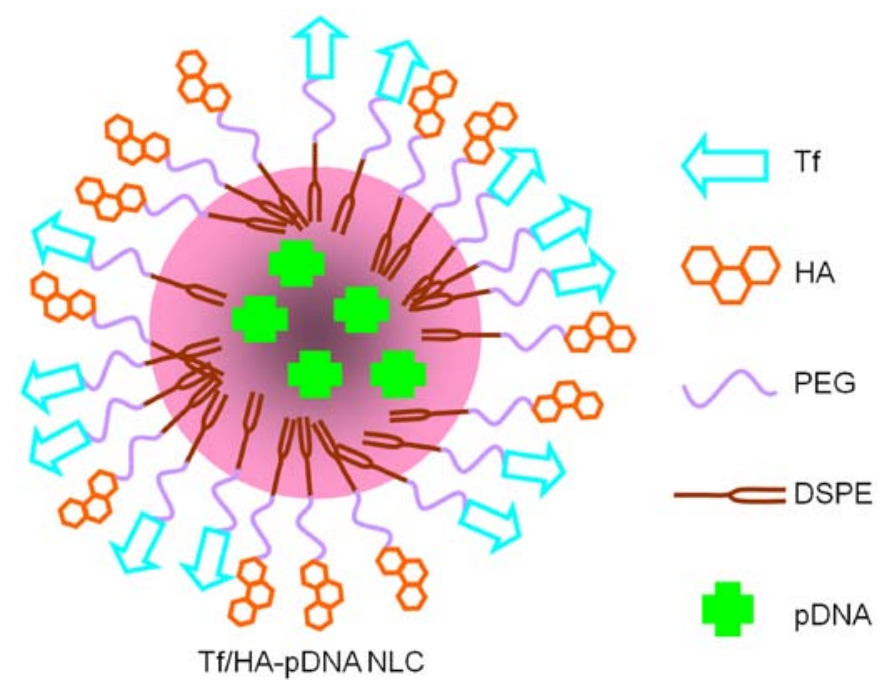

Figure 1. Composition diagram of Tf/HA-pDNA NLC.

HA-PEG-DSPE in total. Non-modified pDNA incorporated NLC (pDNA NLC) was prepared as described above only without Tf-PEG-DSPE and HA-PEG-DSPE in aqueous phase, using $2 \mathrm{~g}$ of PEG-DSPE in total. Blank NLC was prepared as described above without Tf-PEG-DSPE, HA-PEG-DSPE, and pDNA in aqueous phase, using $2 \mathrm{~g}$ of PEG-DSPE dissolved in $40 \mathrm{ml}$ deionized water instead.

Preparation of Lipofectamine 3000 incorporated pDNA. Lipofectamine 3000 incorporated pDNA (pDNA LP) was prepared (27). Briefly, $100 \mu 1$ of pDNA $(1 \mathrm{mg} / \mathrm{ml})$ was mixed with $200 \mu$ l of Lipofectamine 3000 by vortexing for $30 \mathrm{sec}$. The mixture was then incubated for $30 \mathrm{~min}$ at room temperature-facilitated formation of the pDNA LP.

\section{Characterization}

Morphology of Tf/HA-pDNA NLC. Morphology of Tf/ HA-pDNA NLC was characterized by transmission electron microscopy (TEM) (28). Samples were placing onto copper grid and air-drying, followed by negative staining with one drop of a $3 \%$ aqueous solution of sodium phosphotungstate. The air-dried samples were subsequently examined under the transmission electron microscope (JEM-2100; JEOL, Tokyo, Japan).

Particle size and $\zeta$-potential. Particle size, polydispersity index (PDI), and $\zeta$-potential of each sample was measured at room temperature by Zeta Sizer Nano ZS apparatus (Malvern, Southborough, MA, USA) (29). Samples were prepared in disposable capillary cells without dilution. The measurements were performed under conditions of low ionic strength where the surface charge of the particles can be measured accurately. The average particle size was reflected in volume mean diameter.

Gene loading capacity. Gene loading capacity (GL) of each sample was determined by the PicoGreen-fluorometry method (30). Briefly, pDNA was separated from the carriers by centrifugation at $10,000 \mathrm{rpm}$ and $4^{\circ} \mathrm{C}$ for $20 \mathrm{~min}$. The supernatant was collected and the concentration of pDNA
Table I. Particle size, polydispersity index (PDI), $\zeta$-potential, and GL characterization.

\begin{tabular}{lcccc}
\hline Characteristic & $\begin{array}{c}\text { Particle } \\
\text { size (nm) }\end{array}$ & PDI & $\begin{array}{c}\zeta \text {-potential } \\
(\mathrm{mV})\end{array}$ & GL (\%) \\
\hline Tf/HA-pDNA NLC & $189.1 \pm 6.9$ & 0.18 & $+24.3 \pm 3.4$ & $89.6 \pm 2.6$ \\
Tf-pDNA NLC & $183.4 \pm 6.1$ & 0.16 & $+31.5 \pm 4.1$ & $91.1 \pm 2.1$ \\
HA-pDNA NLC & $191.6 \pm 7.2$ & 0.19 & $+20.3 \pm 3.9$ & $88.7 \pm 3.0$ \\
pDNA NLC & $153.4 \pm 5.3$ & 0.14 & $+38.4 \pm 3.2$ & $89.4 \pm 2.4$ \\
Blank NLC & $149.4 \pm 3.8$ & 0.08 & $+46.2 \pm 5.5$ & N/A \\
pDNA LP & $176.1 \pm 5.4$ & 0.12 & $+35.9 \pm 4.4$ & $90.3 \pm 2.8$ \\
\hline
\end{tabular}

NA, not applicable.

was assessed using a fluorescence spectrophotometer (F-4500, Hitachi Science and Technology, Tokyo, Japan).

Serum stability. In terms of serum protection test, samples were immersed in cell culture medium containing $10 \%$ fetal bovine serum and co-incubated at $37^{\circ} \mathrm{C}$ for $24 \mathrm{~h}$. Then samples were tested in terms of size and GL $(31,32)$. At the same time, the naked pDNA was also treated by the same method as a control.

In vitro release studies. The in vitro release studies of NLC were performed in TE buffer (Tris- $\mathrm{HCl} 10 \mathrm{mM}$, EDTA $1 \mathrm{mM}, \mathrm{pH}$ 7.4) (33). Typically, pDNA loaded NLC solution (equivalent to $2 \mu \mathrm{g}$ pDNA) were suspended in $1 \mathrm{ml}$ TE buffer in Eppendorf ${ }^{\circledR}$ tubes at $37^{\circ} \mathrm{C}$ shaking water bath at $100 \mathrm{rpm}$. Separate tubes were used for each data point. At predetermined time intervals, the NLC suspensions were centrifuged $(10,000 \mathrm{rpm}, 20 \mathrm{~min})$ and the amount of DNA released in the supernatant was analyzed by PicoGreen-fluorometry method as indicated above. Background readings were obtained using the supernatants from blank NLC.

In vitro cell viability. In vitro cell viability of each sample in A549 cells was ascertained by MTT colorimetric assay (16). Cells were seeded in a 96-well cell culture plate at an initial density of $10^{5}$ cells/well and incubated in $200 \mu 1$ of RPMI-1640 supplemented with $10 \%$ FBS and antibiotics in $5 \% \mathrm{CO}_{2}$ incubator at $37^{\circ} \mathrm{C}$. After $24 \mathrm{~h}$, the culture medium was replaced by $200 \mu 1$ of fresh serum-free RPMI-1640 medium with different concentrations $(10,20,50,100,150,200 \mu \mathrm{g} / \mathrm{ml})$ of the samples. After incubating for $24 \mathrm{~h}$, the effect of different treatments on cell viability was evaluated by MTT assay. Typically, $5 \mathrm{mg} / \mathrm{ml}$ of MTT in PBS were added to each well reaching a final concentration of $0.5 \mathrm{mg} \mathrm{MTT} / \mathrm{ml}$ and incubated for $4 \mathrm{~h}$. Then the supernatants were removed and the formazan crystals were dissolved in $100 \mu \mathrm{l}$ DMSO. Aliquots were drawn from each well and the absorbance at $570 \mathrm{~nm}$ was determined with a microplate reader (US/680, Bio-Rad, Hercules, CA, USA). Untreated cells were taken as control with $100 \%$ viability and cells without addition of MTT were used as blank to calibrate the spectrophotometer to zero absorbance. The relative cell viability (\%) compared to control cells was calculated by $\mathrm{A}_{\text {sample }} / \mathrm{A}_{\text {control }} \times 100$. 


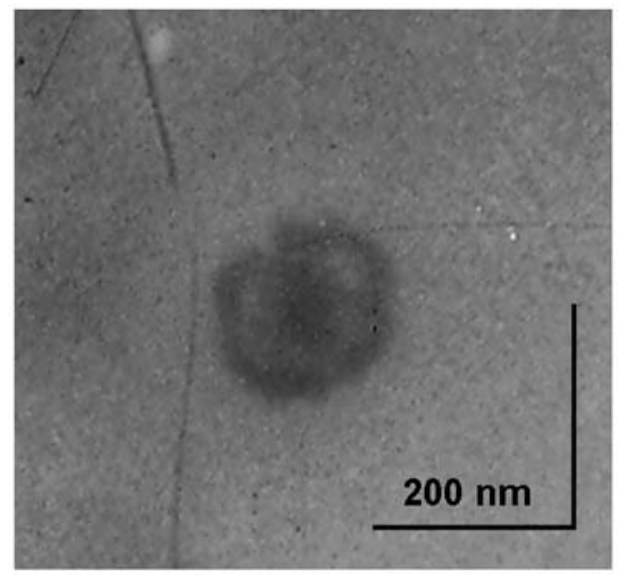

Figure 2. TEM images of Tf/HA-pDNA NLC. Scale bar: $200 \mathrm{~nm}$.

In vitro gene transfection. In vitro gene transfection efficiency studies were evaluated using flow cytometry method. Flow cytometry is a laser- or impedance-based, biophysical technology employed in cell counting, cell sorting, biomarker detection and protein engineering, by suspending cells in a stream of fluid and passing them by an electronic detection apparatus. It allows simultaneous multiparametric analysis of the physical and chemical characteristics of up to thousands of particles per second.

In this study for the cells that were successfully transfected should express green fluorescence and could be detected and quantified after transfection (34). Cells were grown in 6-cm Petri dishes seeding the cells at $10^{5}$ cells/dish. After plating the cells were incubated at $37^{\circ} \mathrm{C}$ for $24 \mathrm{~h}$ and transfection was conducted at approximately $80 \%$ confluence. The culture medium was aspirated from each dish and replaced with $2 \mathrm{ml}$ of serum-free RPMI-1640 medium, containing different samples (each sample contained $10 \mu \mathrm{g}$ pDNA). The cells were incubated in $5 \% \mathrm{CO}_{2}$ incubator at $37^{\circ} \mathrm{C}$ for $12 \mathrm{~h}$. Then, the transfected cells were washed with PBS and incubated at $37^{\circ} \mathrm{C}$ in $5 \mathrm{ml}$ of fresh serum-free RPMI-1640 medium containing FBS for $48 \mathrm{~h}$ to allow the expression of the protein. Cells transfected by $10 \mu \mathrm{g}$ of naked pDNA were utilized as negative control. HA-PTX SLN with no pDNA was used to exclude fluorescence which may be caused by SLN, PTX or HA.

After 36 and $72 \mathrm{~h}$ of incubation, the fluorescent cells were quantified by flow cytometry. The cells were washed with $500 \mu 1$ of PBS and detached with $500 \mu 1$ of $0.25 \%$ trypsin added with EDTA $(1 \%, \mathrm{v} / \mathrm{v})$. Then the cells were centrifuged at $1000 \mathrm{rpm}$, at $4^{\circ} \mathrm{C}$ for $5 \mathrm{~min}$, the supernatant was discarded, and the cells were washed once with $1 \mathrm{ml}$ of PBS, centrifuged again (1000 rpm, $\left.4^{\circ} \mathrm{C}, 5 \mathrm{~min}\right)$, the supernatant was discarded, and the cells were re-suspended in $300 \mu \mathrm{l}$ of PBS and directly introduced to a BD FACSCalibur flow cytometer (Becton Dickinson Medical Device Co. Ltd., Franklin Lakes, NJ, USA).

In vivo gene delivery and expression. For in vivo gene delivery, lung cancer-bearing BALB/c nude mice were randomly divided into several groups and different samples were injected intravenously (24). The untreated group was used as control. The mice were then euthanized at $72 \mathrm{~h}$ after injection, and the tumor tissue samples were removed. The tumor tissues

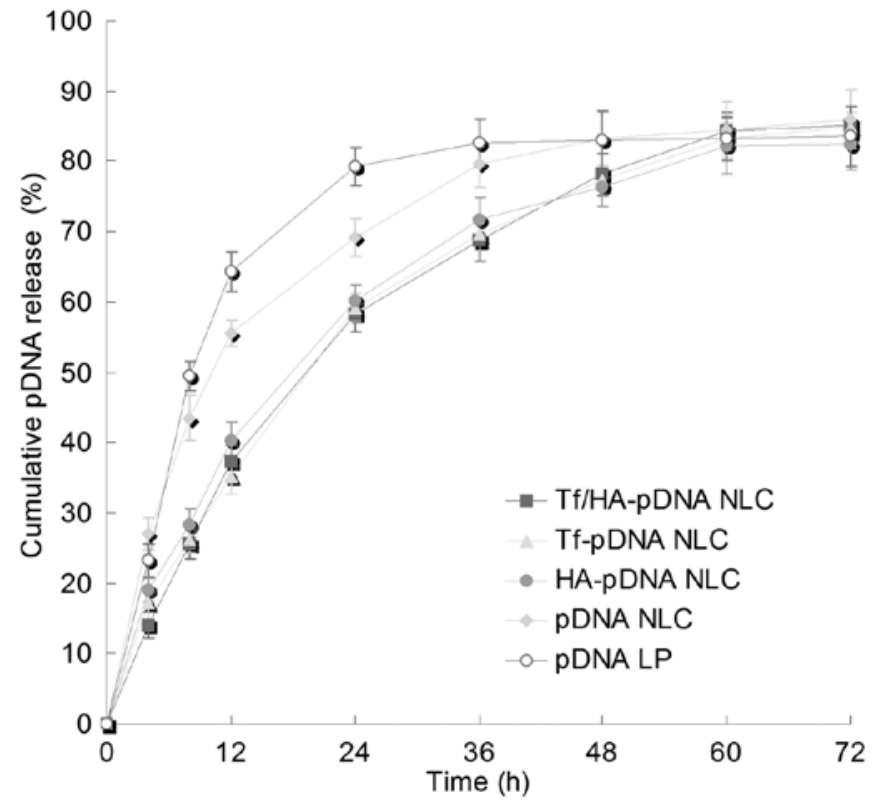

Figure 3. pDNA release profiles of the different systems.

were homogenized by pressing the samples through a $30-\mu \mathrm{m}$ cell mesh with the plunger of a $10-\mathrm{ml}$ syringe. Erythrocyte lysis buffer was added during homogenization to lyse the red blood cells. The homogenates were washed three times with PBS containing $0.5 \%$ bovine serum albumin and then filtered. The cells were obtained after centrifugation $\left(1000 \mathrm{rpm}, 4^{\circ} \mathrm{C}\right.$, $5 \mathrm{~min}$ ) and were seeded into 96-well plates in $1 \mathrm{ml}$ of DMEM with $10 \%$ FBS. The fluorescent cells were washed twice with PBS and cells were directly observed using an inversion fluorescence microscope (BX40, Olympus, Tokyo, Japan). The cells were also quantified by flow cytometry the same way as the 'in vitro gene transfection' section.

Data analysis. The experimental data were analyzed using the Student's t-test. $\mathrm{P}<0.05$ was considered to indicate a statistically significant difference.

\section{Results}

Characterization of Tf/HA-pDNA NLC. Morphology of Tf/ HA-pDNA NLC is exhibited in Fig. 2. Tf/HA-pDNA NLC revealed a core-shell structured spherical morphology with grey coating outside the core, which may be evidence of the modification of $\mathrm{Tf}$ and $\mathrm{HA}$ ligands.

Table I showed that Tf/HA-pDNA NLC had a larger particle size $(189 \mathrm{~nm})$ than pDNA NLC $(153 \mathrm{~nm})$. After the decoration of Tf and HA, $\zeta$-potential of NLC system decreased from $+38 \mathrm{mV}$ (Tf/HA-pDNA NLC) to $+20 \mathrm{mV}$ (Tf/HA-pDNA NLC). The GL of all pDNA loaded systems was $\sim 90 \%$.

Serum stability. Table II described the changes of NLC systems in size and GL in the presence of serum. The NLC systems remained stable up to $24 \mathrm{~h}$ without significant size or GL changes. The results suggest that the NLC was stable in the serum and this may help in the performance of the system in vivo. 


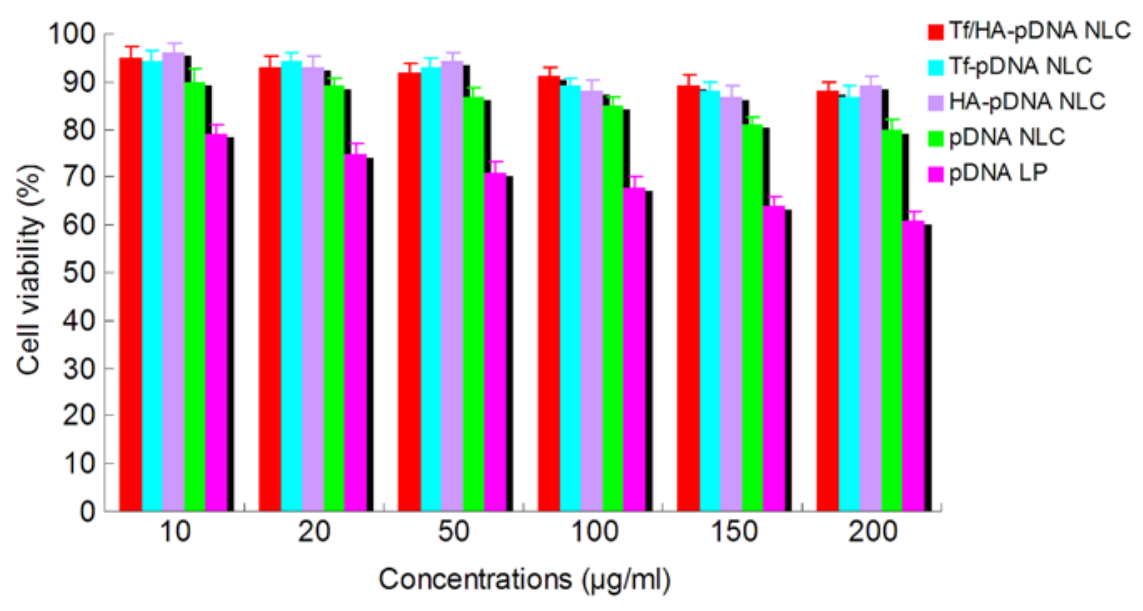

Figure 4. A549 cell viability after treated with different systems.

Table II. Serum stability in 10\% FBS.

\begin{tabular}{lcc}
\hline Systems & Particle size $(\mathrm{nm})$ & GL $(\%)$ \\
\hline Tf/HA-pDNA NLC & $192.3 \pm 8.9$ & $87.2 \pm 3.8$ \\
Tf-pDNA NLC & $187.1 \pm 9.4$ & $88.6 \pm 3.4$ \\
HA-pDNA NLC & $194.6 \pm 10.1$ & $85.9 \pm 4.2$ \\
pDNA NLC & $156.9 \pm 7.3$ & $86.3 \pm 5.1$ \\
Blank NLC & $152.4 \pm 6.3$ & N/A \\
\hline
\end{tabular}

NA, not applicable.

In vitro release. Fig. 3 illustrates the pDNA release profiles of NLC systems. The pDNA release of Tf and/or HA decorated NLC was slower than undecorated NLC. The release of pDNA from different decorated NLC did not appear significantly different. The release of pDNA LP was faster than the NLC systems.

In vitro cell viability. Fig. 4 showed the viability of A549 cells after treated with different NLC systems. The cell viabilities in the presence of NLC systems over the studied concentration range were $>80 \%$. NLC systems exhibited lower cytotoxicity than pDNA LP at all concentrations $(\mathrm{P}<0.05)$. Tf and/or HA decorated NLC showed higher cell viability than undecorated NLC at the concentrations of 150 and $200 \mu \mathrm{g} / \mathrm{ml}$.

In vitro gene transfection. As showed in Fig. 5, Tf/HA-pDNA NLC exhibited significantly higher gene transfection efficiency than Tf-pDNA NLC and HA-pDNA NLC at both 36 and $72 \mathrm{~h}$ after administration $(\mathrm{P}<0.05)$. Tf and/or HA decorated pDNA loaded NLC systems had obviously better ability than undecorated pDNA NLC at 36 and $72 \mathrm{~h}(\mathrm{P}<0.05)$. pDNA NLC displayed no obvious deference to pDNA LP ( $>0.05)$. Tf-pDNA NLC displayed better capacity than HA-pDNA NLC at $72 \mathrm{~h}(\mathrm{P}<0.05)$. Naked pDNA and blank NLC did not have any outcome in the quantitation study.

In vivo gene delivery and expression. Fig. 6 illustrates the fluorescence images of A549 cells when the different

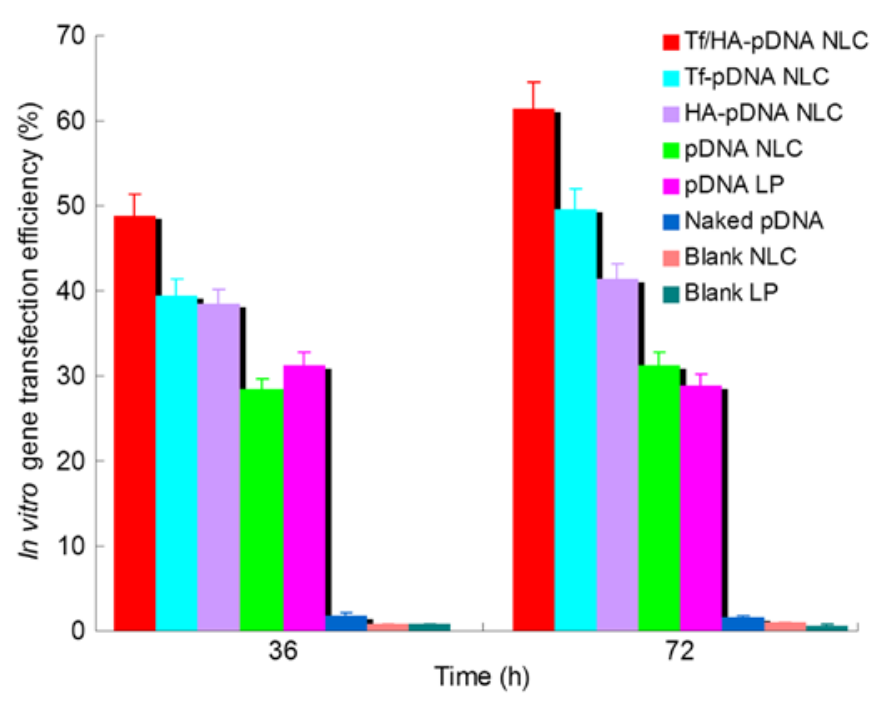

Figure 5. In vitro gene transfection efficiency of different systems on A549 cells.

systems were delivered in vivo. The best green fluorescence expression was obtained by Tf/HA-pDNA NLC according to the images. Decorated pDNA loaded NLC systems had better performance than undecorated NLC and pDNA LP. Naked pDNA and blank NLC had no green fluorescence in the images.

The in vivo transfection efficiency of the fluorescent cells was quantified using flow cytometry, as shown in Fig. 7. Tf/ HA-pDNA NLC displayed higher transfection efficiency than Tf-pDNA NLC, which was higher than HA-pDNA NLC $(\mathrm{P}<0.05)$. pDNA loaded NLC systems had obviously better ability than pDNA LP $(\mathrm{P}<0.05)$. The in vivo quantification results were in accordance with the qualitative images and the in vitro quantification results.

\section{Discussion}

In this study, we used dual ligand-modified NLC as nanocarrier for the targeted delivery of gene to tumor site. Firstly, Tf-PEG-DSPE and HA-PEG-DSPE were synthesized and 

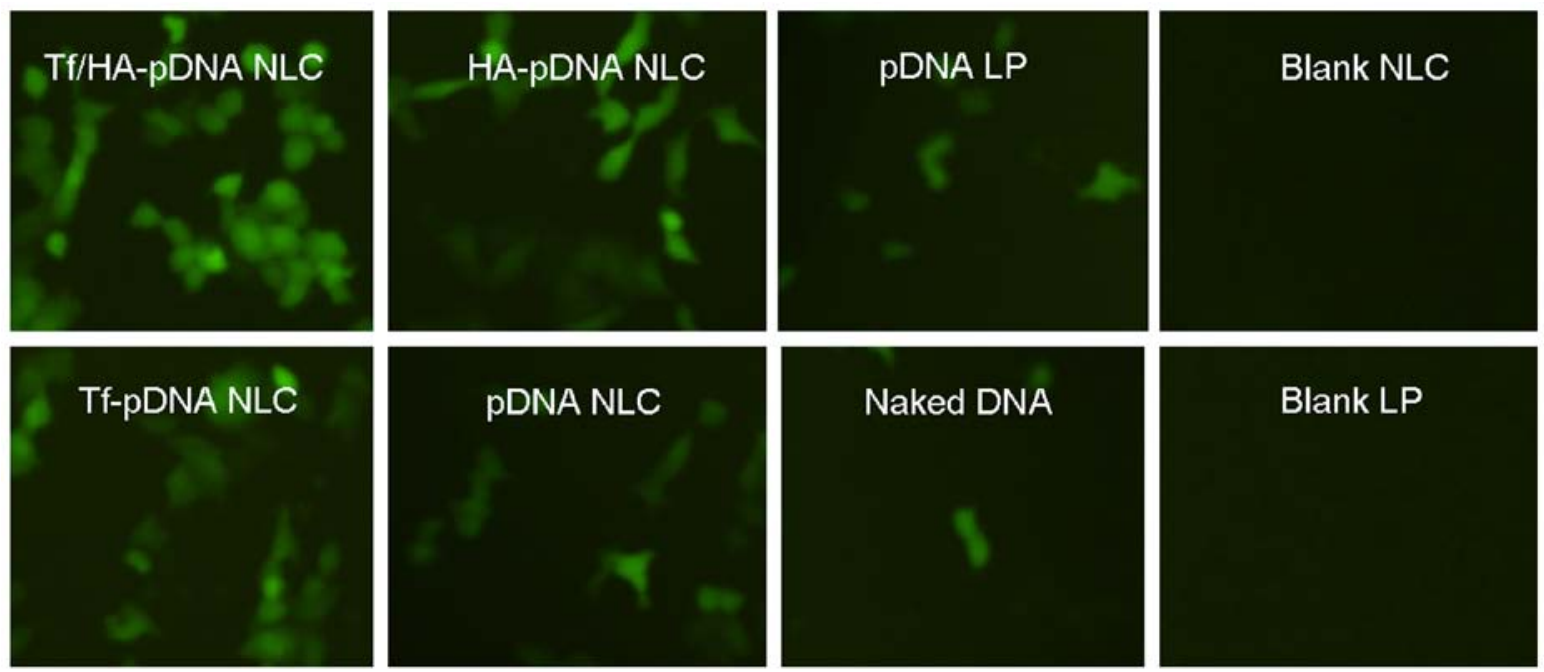

Figure 6. Fluorescence images of A549 cells transfected by different systems.

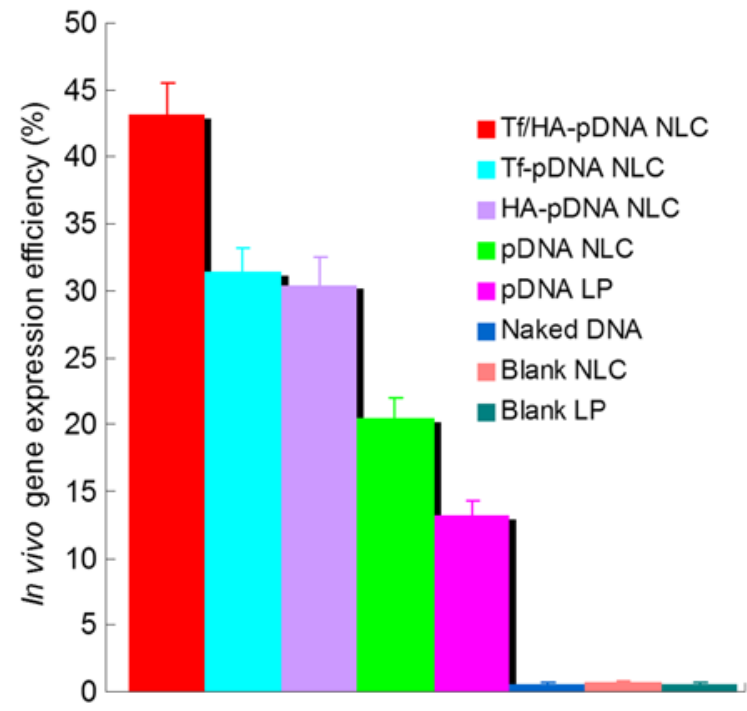

Figure 7. In vivo gene expression results of different systems on lung cancerbearing mice.

analyzed. Then Tf/HA-pDNA NLC was prepared and characterized.

TEM was used to explore the structure and morphology of Tf/HA-pDNA NLC (Fig. 2). The images reveal that Tf/HA-pDNA NLC has a core-shell spherical structure with grey coating outside the core. The shell structure may prove the existence of Tf and HA ligands. Surface morphology has been demonstrated to be important in determining the uniformity and stability of the system (35). The size and $\zeta$-potential of NPs not only determine their colloidal stability but also influence the effectiveness of their interaction with cell membranes, which is the key step for successful cellular uptake (36). Tf/HA-pDNA NLC had a larger size and lower $\zeta$-potential than that of pDNA NLC, indicating that anionic Tf and HA successfully decorated the surface of NLC, enlarged the size and neutralized the charge of the pDNA NLC. All the NLC samples tested have positive surface charge, which is necessary to ensure the uptake of complexes by cells due to electrostatic interactions between the carriers and the negatively charged cellular membranes.

The GL of pDNA loaded NLC systems was 90\%.pDNA was anionic materials, cationic materials of NLC system could efficiently adsorb and incorporate anionic plasmid, primarily via ionic interaction, which depends on the charge attraction $(32,37)$. Serum stability of NLC systems was evaluated in $10 \%$ FBS in order to evaluate the stability of the NLC intravenous administration. The results illustrated that these carriers would not collapse or accumulate in blood circulation (38). pDNA loaded in the systems was well protected and was not damaged by the serum. This behavior could be helpful with the in vivo effect of the gene delivery system.

Sustained-release property of the nanocarriers is significant for gene therapy (39). More sustained pDNA release behavior of Tf/HA-pDNA NLC than undecorated pDNA NLC could be explained by the modification of ligands influencing the release property of the NLC system. The sustained release can give continuous protection of the pDNA and lead to the persistent therapeutic effect.

Lipid carriers have cytotoxic drawbacks, especially when cationic lipids are involved (40). Cationic formulations have been described to affect cell proliferation, differentiation, and pro-apoptotic genes in human epithelial cells. Therefore, evaluation of the cytotoxicity of the cationic gene delivery systems is essential. The cell viabilities in the presence of NLC systems were high. Lower cytotoxicity of NLC systems than pDNA LP system suggested the favorable tolerance of the NLC. Tf and/or HA decorated NLC showed higher cell viability than undecorated ones, indicating the decoration of ligands may have influence on the surface character of the NLC system and provide better cell viability.

In vitro and in vivo gene transfection study intended to evaluate the ability of ligands decorated NLC systems to transfer the pDNA to A549 lung cancer cells and lung cancer-bearing mouse model was reported (30). Intracellular trafficking, gene expression and subsequent protein synthesis are required for an efficient gene delivery system to be accomplish $(41,42)$. The commercial cationic liposome based 
reagent, Lipofectamine 3000, well known to provide high transfection efficiency and high level of transgene expression in a range of mammalian cell types was chosen as positive control in our study. Higher gene transfection efficiency achieved by Tf/HA-pDNA NLC than Tf-pDNA NLC and HA-pDNA NLC could be evidence of better target ability of the dual ligand-decorated NLC system. Better ability exhibited by pDNA loaded NLC systems than pDNA LP in the animal model showed the superiority of the NLC vectors compared to the liposomes when delivered in vivo. Tf-pDNA NLC displayed better capacity than HA-pDNA NLC at $72 \mathrm{~h}$ could be proof of better affinity of Tf than HA ligands after a period of administration. The test of naked pDNA and blank NLC samples influenced the gene and NLC materials on the transfection result. As expected, significant gene transfer effects of Tf/HA-pDNA NLC in lung cancer cells through intravenous injection were observed without toxicity. Tf/ HA-pDNA NLC could be a promising gene delivery system for lung cancer gene therapy.

In summary, Tf and HA containing ligands were synthesized and used for the decoration of lipid carriers. Tf/HA-pDNA NLC was developed as an efficient and safe gene delivery system. The dual ligand-decorated, pDNA loaded NLC system had low cytotoxicity and exhibited enhanced gene transfer ability in vitro as well as in vivo. Therefore, Tf/HA-pDNA NLC has the potential to be a safe and efficient gene carrier for lung cancer gene therapy.

\section{References}

1. Siegel R, Ma J, Zou Z and Jemal A: Cancer statistics, 2014. CA Cancer J Clin 64: 9-29, 2014.

2. Poulsen TT, Pedersen N and Poulsen HS: Replacement and suicide gene therapy for targeted treatment of lung cancer. Clin Lung Cancer 6: 227-236, 2005.

3. Stuckey DW and Shah K: Stem cell-based therapies for cancer treatment: Separating hope from hype. Nat Rev Cancer 14: 683-691, 2014

4. Zhang TY, Huang B, Wu HB, Wu JH, Li LM, Li YX, Hu YL, Han M, Shen YQ, Tabata Y, et al: Synergistic effects of co-administration of suicide gene expressing mesenchymal stem cells and prodrug-encapsulated liposome on aggressive lung melanoma metastases in mice. J Control Release 209: 260-271, 2015.

5. Cho WY, Hong SH, Singh B, Islam MA, Lee S, Lee AY, Gankhuyag N, Kim JE, Yu KN, Kim KH, et al: Suppression of tumor growth in lung cancer xenograft model mice by poly(sorbitol-co-PEI)-mediated delivery of osteopontin siRNA Eur J Pharm Biopharm 94: 450-462, 2015.

6. Kim I, Byeon HJ, Kim TH, Lee ES, Oh KT, Shin BS, Lee KC and Youn YS: Doxorubicin-loaded porous PLGA microparticles with surface attached TRAIL for the inhalation treatment of metastatic lung cancer. Biomaterials 34: 6444-6453, 2013.

7. Merdan T, Kopecek $J$ and Kissel T: Prospects for cationic polymers in gene and oligonucleotide therapy against cancer. Adv Drug Deliv Rev 54: 715-758, 2002.

8. Xie RL, Jang YJ, Xing L, Zhang BF, Wang FZ, Cui PF, Cho MH and Jiang HL: A novel potential biocompatible hyperbranched polyspermine for efficient lung cancer gene therapy. Int J Pharm 478: 19-30, 2015

9. Christensen CL, Zandi R, Gjetting T, Cramer F and Poulsen HS: Specifically targeted gene therapy for small-cell lung cancer Expert Rev Anticancer Ther 9: 437-452, 2009.

10. Chen Y, Gao DY and Huang L: In vivo delivery of miRNAs for cancer therapy: Challenges and strategies. Adv Drug Deliv Rev 81: 128-141, 2015.

11. Chen Y, Zhu X, Zhang X, Liu B and Huang L: Nanoparticles modified with tumor-targeting scFv deliver siRNA and miRNA for cancer therapy. Mol Ther 18: 1650-1656, 2010.
12. Lennox KA and Behlke MA: Chemical modification and design of anti-miRNA oligonucleotides. Gene Ther 18: 1111-1120, 2011.

13. Tivnan A, Orr WS, Gubala V, Nooney R, Williams DE, McDonagh C, Prenter S, Harvey H, Domingo-Fernández R, Bray IM, et al: Inhibition of neuroblastoma tumor growth by targeted delivery of microRNA-34a using anti-disialoganglioside GD2 coated nanoparticles. PLoS One 7: e38129, 2012.

14. Heger Z, Gumulec J, Cernei N, Tmejova K, Kopel P, Balvan J, Masarik M, Zitka O, Beklova M, Adam V, et al: 17 $\beta$-estradiolcontaining liposomes as a novel delivery system for the antisense therapy of ER-positive breast cancer: An in vitro study on the MCF-7 cell line. Oncol Rep 33: 921-9, 2015.

15. de Jesus MB and Zuhorn IS: Solid lipid nanoparticles as nucleic acid delivery system: Properties and molecular mechanisms. J Control Release 201: 1-13, 2015.

16. Zhang Z, Sha X, Shen A, Wang Y, Sun Z, Gu Z and Fang X: Polycation nanostructured lipid carrier, a novel nonviral vector constructed with triolein for efficient gene delivery. Biochem Biophys Res Commun 370: 478-482, 2008.

17. Doktorovova S, Souto EB and Silva AM: Nanotoxicology applied to solid lipid nanoparticles and nanostructured lipid carriers - a systematic review of in vitro data. Eur J Pharm Biopharm 87: $1-18,2014$.

18. Han Y, Zhang Y, Li D, Chen Y, Sun J and Kong F: Transferrinmodified nanostructured lipid carriers as multifunctional nanomedicine for codelivery of DNA and doxorubicin. Int J Nanomed 9: 4107-4116, 2014.

19. Avitabile T, Marano F, Castiglione F, Bucolo C, Cro M, Ambrosio L, Ferrauto $\mathrm{C}$ and Reibaldi A: Biocompatibility and biodegradation of intravitreal hyaluronan implants in rabbits. Biomaterials 22: 195-200, 2001.

20. Fang XJ, Jiang H, Zhu YQ, Zhang LY, Fan QH and Tian Y: Doxorubicin induces drug resistance and expression of the novel CD44st via NF- $\kappa \mathrm{B}$ in human breast cancer MCF-7 cells. Oncol Rep 31: 2735-2742, 2014.

21. Coradini D, Pellizzaro C, Abolafio G, Bosco M, Scarlata I, Cantoni S, Stucchi L, Zorzet S, Turrin C, Sava G, et al: Hyaluronic-acid butyric esters as promising antineoplastic agents in human lung carcinoma: A preclinical study. Invest New Drugs 22: 207-217, 2004.

22. Pan J, Sun SK, Wang Y, Fu YY, Zhang X, Zhang Y and Yu C: Facile preparation of hyaluronic acid and transferrin co-modified $\mathrm{Fe}_{3} \mathrm{O}_{4}$ nanoparticles with inherent biocompatibility for dualtargeting magnetic resonance imaging of tumors in vivo. Dalton Trans 44: 19836-19843, 2015.

23. Kondo H, Miyoshi K, Sakiyama S, Tangoku A and Noma T: Differential regulation of gene expression of alveolar epithelial cell markers in human lung adenocarcinoma-derived A549 clones. Stem Cells Int 2015: 165867, 2015.

24. Wang W, Zhou F, Ge L, Liu X and Kong F: Transferrin-PEG-PE modified dexamethasone conjugated cationic lipid carrier mediated gene delivery system for tumor-targeted transfection. Int J Nanomed 7: 2513-2522, 2012.

25. Jing L, Shao S, Wang Y, Yang Y, Yue X and Dai Z: Hyaluronic acid modified hollow Prussian blue nanoparticles loading 10-hydroxycamptothecin for targeting thermochemotherapy of cancer. Theranostics 6: 40-53, 2016.

26. Zhang XG, Miao J, Dai YQ, Du YZ, Yuan H and Hu FQ: Reversal activity of nanostructured lipid carriers loading cytotoxic drug in multi-drug resistant cancer cells. Int J Pharm 361: 239-244, 2008.

27. Du YZ, Cai LL, Li J, Zhao MD, Chen FY, Yuan H and Hu FQ: Receptor-mediated gene delivery by folic acid-modified stearic acid-grafted chitosan micelles. Int J Nanomed 6: 1559-1568, 2011.

28. Yu W, Liu C, Liu Y, Zhang N and Xu W: Mannan-modified solid lipid nanoparticles for targeted gene delivery to alveolar macrophages. Pharm Res 27: 1584-1596, 2010.

29. Wang RH, Cao HM, Tian ZJ, Jin B, Wang Q, Ma H and Wu J: Efficacy of dual-functional liposomes containing paclitaxel for treatment of lung cancer. Oncol Rep 33: 783-791, 2015.

30. Yu W, Liu C, Ye J, Zou W, Zhang $\mathrm{N}$ and Xu W: Novel cationic SLN containing a synthesized single-tailed lipid as a modifier for gene delivery. Nanotechnology 20: 215102, 2009.

31. Pepić I, Lovrić J, Hafner A and Filipović-Grčić J: Powder form and stability of Pluronic mixed micelle dispersions for drug delivery applications. Drug Dev Ind Pharm 40: 944-951, 2014.

32. Yu X, Yang G, Shi Y, Su C, Liu M, Feng B and Zhao L: Intracellular targeted co-delivery of shMDR1 and gefitinib with chitosan nanoparticles for overcoming multidrug resistance. Int J Nanomed 10: 7045-7056, 2015. 
33. Zou W, Liu C, Chen Z and Zhang N: Studies on bioadhesive PLGA nanoparticles: A promising gene delivery system for efficient gene therapy to lung cancer. Int J Pharm 370: 187-195, 2009.

34. Vighi E, Montanari M, Hanuskova M, Iannuccelli V, Coppi G and Leo E: Design flexibility influencing the in vitro behavior of cationic SLN as a nonviral gene vector. Int J Pharm 440: 161-169, 2013.

35. Hazzah HA, Farid RM, Nasra MM, El-Massik MA and Abdallah OY: Lyophilized sponges loaded with curcumin solid lipid nanoparticles for buccal delivery: Development and characterization. Int J Pharm 492: 248-257, 2015.

36. Wang L, Dong J, Ouyang W, Wang X and Tang J: Anticancer effect and feasibility study of hyperthermia treatment of pancreatic cancer using magnetic nanoparticles. Oncol Rep 27: 719-726, 2012.

37. Ravi Kumar MN, Bakowsky U and Lehr CM: Preparation and characterization of cationic PLGA nanospheres as DNA carriers. Biomaterials 25: 1771-1777, 2004.
38. Immordino ML, Brusa P, Rocco F, Arpicco S, Ceruti M and Cattel L: Preparation, characterization, cytotoxicity and pharmacokinetics of liposomes containing lipophilic gemcitabine prodrugs. J Control Release 100: 331-346, 2004.

39. Song RF, Li XJ, Cheng XL, Fu AR, Wang YH, Feng YJ and Xiong Y: Paclitaxel-loaded trimethyl chitosan-based polymeric nanoparticle for the effective treatment of gastroenteric tumors. Oncol Rep 32: 1481-1488, 2014

40. Torchilin VP: Multifunctional nanocarriers. Adv Drug Deliv Rev 58: 1532-1555, 2006.

41. Kamiya H, Tsuchiya $H$, Yamazaki $J$ and Harashima $H$ : Intracellular trafficking and transgene expression of viral and non-viral gene vectors. Adv Drug Deliv Rev 52: 153-164, 2001.

42. Jiang HL, Hong SH, Kim YK, Islam MA, Kim HJ, Choi YJ, Nah JW, Lee KH, Han KW, Chae C, et al: Aerosol delivery of spermine-based poly(amino ester)/Akt1 shRNA complexes for lung cancer gene therapy. Int J Pharm 420: 256-265, 2011. 